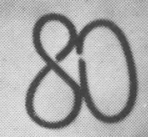

Fig. 1.-Calculus in Ureter. 


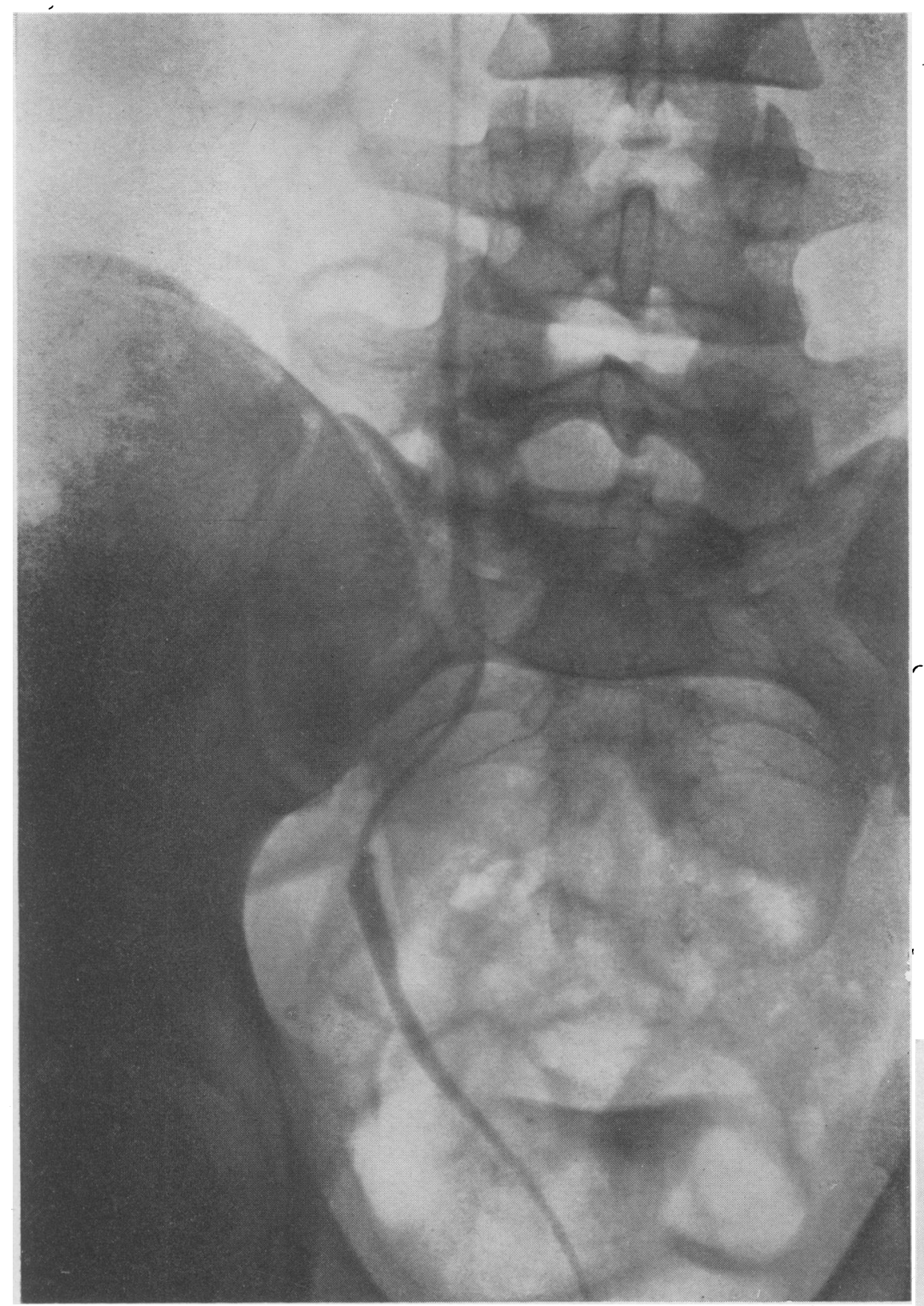

Fig. 2.-Calculus in Ureter.

FIg. 4.-Calculus in Appendix.

February, 1947 


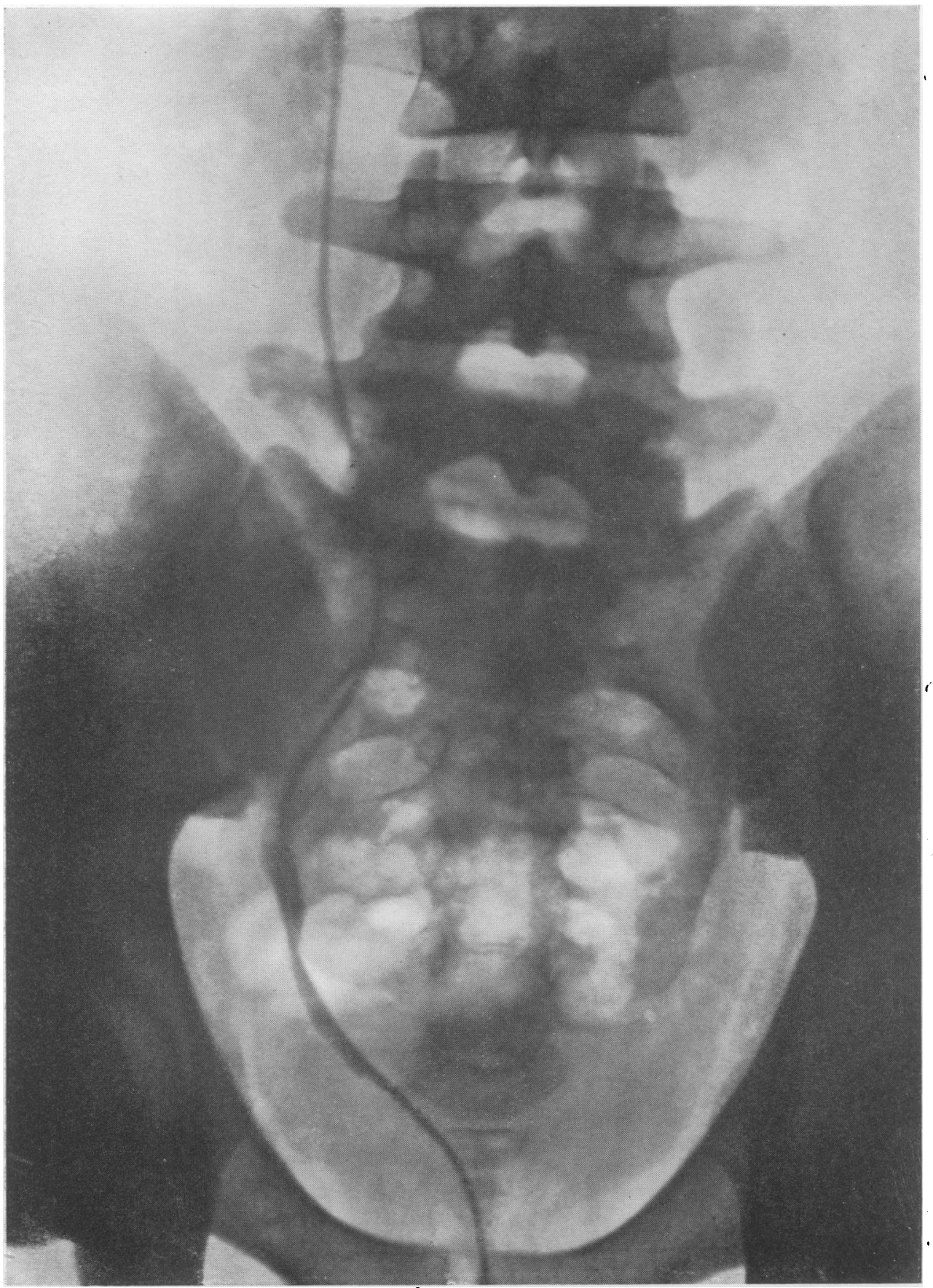

Fig. 3.-Calculus not in ureter. 
Diagrams composed from tracings of a very large number of $\mathrm{X}$-rays taken of the case quoted in the text.
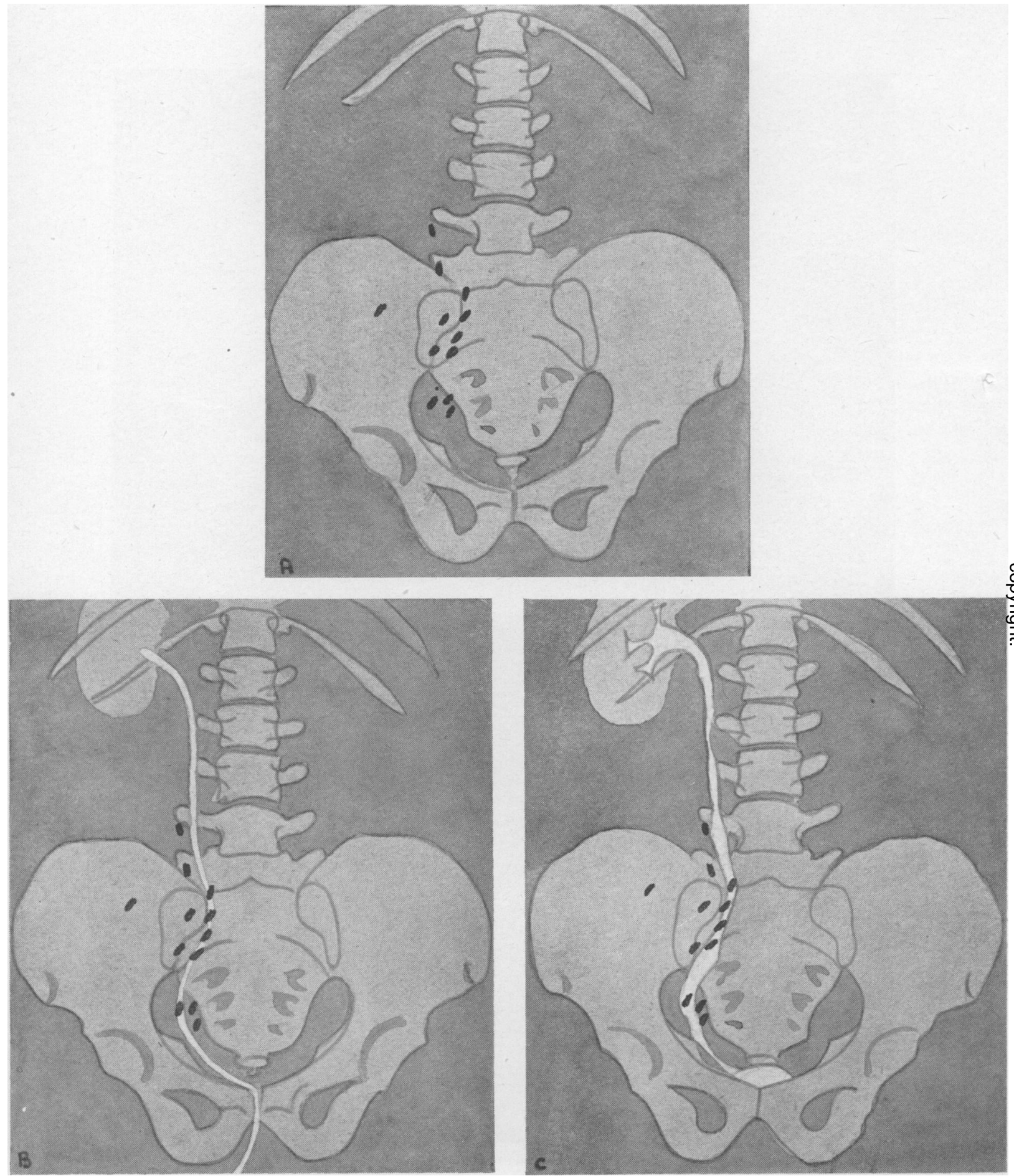

' A' showing the different positions of the 'calculus' on straight X-ray, the majority of which might well be in the ureter.
' B' showing ureteric catheter in place. Five of the twelve positions are in the line of the ureter.
' C' I. V. Pyelogram.-The varying diameter of the ureter and relatively indistinct outline allows for even greater error.

Throughout the history of investigations four pyelograms were done, three of which showed the 'calculus' in the line of the ureter. At operation the 'calculus' was found in the appendix. 


\title{
CALCULUS IN THE APPENDIX SIMULATING URETERIC CALCULUS
}

\author{
By R. S. HunT, F.R.C.S.E. \\ Lieut.-Col., R.A.M.C.
}

The following record of a case of appendicular colic is offered as illustrating some interesting features :-

In November, 1945, Sgmn. G.T., aged 19 years, developed an ache in the right side of the abdomen below the umbilicus. He thought this was due to bruising from a kick he received at football that afternoon. The same evening he had a sudden, severe, shooting pain whith radiated from the right hypochondrium to the right testis. He was admitted to the first of a series of hospitals where he has been under investigation.

He had straight X-rays of the abdomen and a barium meal. A diagnosis of 'calculus in the ureter' was made and he was told it would probably pass naturally. He was discharged I4 days after admission. Apart from colic he had slight difficulty in starting micturition which he again put down to bruising and muscle stiffness. There was never any haematuria nor any abnormality found in his urine.

He continued to have severe attacks of colic at intervals of a week or so and two months later was again admitted to a second hospital. $\mathrm{He}$ had straight X-rays, an I.V.P. and a cystoscopy. Again a diagnosis of 'calculus in the ureter' was made and he was told to drink plenty and take exercise as it would probably pass naturally. Again there was no haematuria nor any abnormality in the urine.

The attacks of colic became more frequent and severe and whilst at the convalescent depot he fainted during an attack and was admitted to his third hospital. The same in- vestigations were made with a retrograde pyelogram in addition, the same diagnosis made and the same instructions given.

Ten days later he was re-admitted with another attack of colic. Operation was advised, but not done, partly because the surgeon himself was ill and partly because a last minute $\mathrm{X}$-ray report stated that the 'calculus had moved down.' A few days later the patient was back with his unit.

During the exertions of a unit move he had another attack of colic and was admitted into his fourth hospital. Previous X-rays were not available and more were taken. The 'calculus' was still present, but owing to inadequate operating facilities he was transferred to his fifth hospital for operation. Here, for the first time, a retrograde pyelogram (Fig. 3) showed the 'calculus' to be outside the line of the ureter. It was still considered to be the cause of the trouble however and probably a concretion in the appendix.

On October 17th, 1946, almost a year after the onset of symptoms, the appendix was removed and before it was opened it was X-rayed to reveal the 'calculus' embedded between faecaliths and distal to a stricture (Fig. 4).

\section{Comment}

(a) It is interesting to see the wide range of movement of the appendix so well demonstrated in the composite diagrams, Figs. A, B and $\mathrm{C}$.

(b) To realize that appendicular colic is still a differential diagnosis of ureteral colic, in spite of the teaching that as the gut is 
developmentally a midline structure, pain originating in it is referred to the umbilicus.

(c) To note the missed significance of a negative finding, i.e. there was never any abnormality in the urine.

(d) To appreciate the value of stereoscopic views in any case of doubt. In this vast series of X-rays only one pyelogram revealed, beyond doubt, that the 'calculus' was not in the ureter. It took a year to get it! Four previous pyelograms had unfortunately been taken when the stone was directly in line with the ureter. One such pyelogram among many which suggest the opposite makes its significance the more important and at the same time, less obvious.

(e) It is curious that this concretion could produce such severe symptoms and yet leave the appendix so little affected. At operation the appendix appeared perfectly normal except for a small adhesion at its base binding it down to the posterior parietal peritoneum, presumably in close relation to the ureter.

(f) Ultimate negative X-ray and freedom from symptoms on the part of the patient make the diagnosis beyond doubt.

I have to thank the Director-General Army Medical Service for permission to publish this case.

GOLD MEDAL, International Congress of Medicine, 1913. Throughout the war, NOVOCAIN

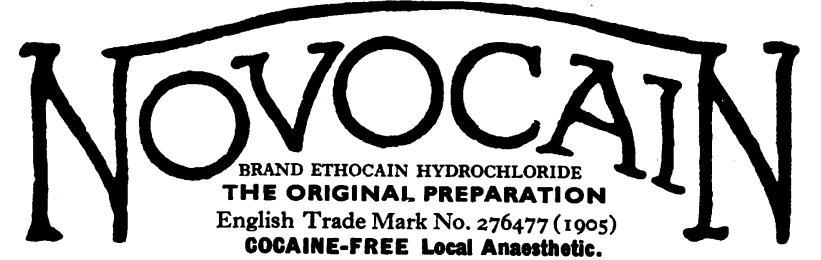
preparations continued to be available in all forms, viz. :

Solutions in Ampoules, 1 oz. and 2 oz. Bottles, Stoppered or Rubber Capped. Tablets in various sizes, Powders, Etc.

Prices have been maintained at pre-war levels Six to seven times less tonic than Cocaine LITERATURE AND FULL TECHNIQUE ON REQUEST SOLD UNDER AGREEMENT.

\section{THE SACCHARIN CORPORATION, LIMITED 84 MALFORD GROVE, SNARESBROOK, LONDON, E.I8.

